\title{
Nurse Interns' Satisfaction with Clinical Learning Environment in Intensive Care Unit
}

\author{
Suad El-Syed A. El-Saman ${ }^{(1)}$, Eman Hassan A. Makhlof ${ }^{(2)}$ \\ Lecturer, Critical Care and Emergency Nursing Department, Faculty of Nursing, Alexandria University, \\ Alexandria, Egypt. \\ Nurse, Causality Care Unite I, Teaching Main University Hospital, Alexandria University, Alexandria, Egypt
}

\begin{abstract}
:
Background: Integration of nursing theory into practice is a vital concern of educational organization. Satisfied clinical environment influences not only educational goals, but also affect nurse students' choices of future career. Intensive care unit (ICU) is appreciated learning environment which allow a great chance for nurse interns (NIs) to get training through internship year. ICU is a multidimensional unit which has a straight influence on the conclusions of NIs' clinical training. Understanding these dimensions is the first step toward enhancing learning and training to ensure safety and quality of patient care.

Objective: To assess nurse interns' satisfaction with clinical learning environment (CLE) in intensive care unit. Method: One hundred NIs who received training in three selected ICUs of Teaching Main University Hospital, Alexandria, Egypt. ICUs were Causality Care Unite I, General Intensive Care Unit II, and General Intensive Care Unit III.

Tool: "Clinical Learning Environment, Supervision and Nurse Teacher (CLES $+T)$ evaluation scale" tool was used. The period of study was from April 2016 to October 2016.

Results : the present study showed that the majority of NIs were in the age group from 20 to 29 years old (90\%), female (83\%), and single (70\%), as well as more than half of them (64\%) had experience from 1 to 5 years in ICU. There was significant relation between the overall general NIs' satisfaction and all of the studied CLE dimensions $(p=0.00$ for all dimensions). NIs perceived that pedagogical atmosphere was the most important dimension in CLE while leadership style of ICU manager was the least one. In addition, high percent of NIs with age below 20 years perceived dimension of premises of nursing in ICU as the most vital dimension $(P=0.001)$ while NIs with age from 20 to 29 years perceived dimension of nurse preceptor role as the most vital one $(P=0.001)$. Furthermore, a significant correlation between NIs' experience of working in ICU and both $C L E$ dimensions of nurse preceptor role $(p=0.003)$ and supervisory relationship $(p=0.04)$.

Conclusions: From the current study, it can be concluded that nurse interns were generally satisfied with CLE dimensions. Moreover, significant relation between NIs' socio-demographic data of age, gender, marital status with their satisfaction with the five CLE dimensions. Further study is needed to investigate the impact of CLE improvement on NIs' performance.
\end{abstract}

Key words: clinical learning environment, nurse intern, preceptor, satisfaction, supervisor.

\section{Introduction}

Nursing is a clinical founded field so integrating theoretical nursing with practice is the key of professional progress. For accomplishing this integration and obtaining intended learning outcomes, an accommodating clinical environment is needed which is important for transporting knowledge in practice basis. It was documented that clinical learning is a vital part of nursing curriculum. Based on this clinical learning importance, nursing program of Bachelor of Science contained course of internship training through a final year. This course is related to different specialty of nursing such as medical, surgical, critical care, pediatric, and obstetric. Nurse interns (NIs) are nurse students will be trained clinically through these specialties. ${ }^{(1)}$

Concerning critical care nursing, intensive care units can ascertain to be appreciated learning environment permitting NIs to take part in care of critically ill patient demanding basic and advanced nursing care. ${ }^{(2)}$ Smedley ${ }^{(3)}$ defined clinical learning environment (CLE) in nursing as learning derived from situations or learning inside the actual environment. Additionally, Chan ${ }^{(4)}$ documented that CLE, as a multidimensional unit which has a straight influence on the conclusions of nurse intern clinical training. Clinical engagements provide NIs with a chance to practice nursing in actual reality and perfectly enable nurse intern to place theory into training. It was advised that nursing program success is greatly dependent on competence of clinical training. Several evidences advocated that ICU clinical environment consists of many aspects including educational atmosphere, premises of nursing in ICU, leadership style of ICU manager, and preceptor \& supervisor roles. ${ }^{(5)}$ 
Concerning educational atmosphere, it reflects the accessibility to the unit staff, interest in intern nurses' supervision and presence of meaningful \& multidimensional learning situation. Also, it helps NIs to feel comfortable going to ICU and taking part in the discussion during nursing round. For premises of nursing in ICU, it concerns availability of a clearly defined nursing philosophy, individualization of nursing care and presence of a clearly defined ICU protocols. Moreover, hospital and university coordination should be attained to achieve the intended learning objective. This may affirm a harmony of tasks and concerns between hospital goals and educational ones. ${ }^{(6)}$ Regarding contributing roles in learning process, supervisor role in ICU is particularly influential. Not only they supervised nursing staff members, but also serve as role-models for nursing practice. ${ }^{(7)}$ Otron ${ }^{(8)}$, Fretwell ${ }^{(9)}$ described the influence of the nurse supervisor in determining the attitude of staff toward intern nurse and the quality of teaching which nurse intern encounters during the clinical experience , and concluded that nurse supervisor were pivotal figures in generating and commanding clinical learning environment. Regarding preceptor role, they are nurse teachers, who defined by Borrageiro ${ }^{(10)}$ as a qualified nurse teacher employed by faculty. Their role includes setting the learning goals, enabling integration of theory and practice, supervision, giving constructive feedback, etc.

It is approved that if NIs experience disadvantaged care environments and poor quality of nursing care, they may develop undesirable approach to critically ill patients' care. Also, it is expected that a good learning environment will enhance nurse intern training. On the other hand, an encouraging work and learning environment seems to be essential in attracting nurses' recruitment in ICU later on. ${ }^{(11,12)}$ However, some researches displayed that the CLE is a significant element with reference to learning goals, ${ }^{(13,14)}$ we found few studies describing the clinical learning environment in ICU specifically, and we debate that this is necessary considering the ever increasing need to recruit and retain nurses to critically ill patients' care. Understanding aspects involving in clinical learning environment is the first step toward enhancing learning and training to ensure safety and quality of patient care. Therefore we achieved this study to assess the most important aspects influencing nurse interns' satisfaction of clinical learning environment of ICU which can lead to improve learning, patient safety, diminish improper nursing practices that impact patient morbidity and mortality, and decreasing cost of patient care.

The aim of this study is to assess nurse interns' satisfaction with clinical learning environment in intensive care unit

Research questions: What are the most important aspects influencing nurse interns' satisfaction of their clinical learning environment in intensive care unit?

\section{Materials and Method}

Design: A descriptive research design was used.

Setting: The study was conducted in three intensive care units (ICUs) in Teaching Main University Hospital, Alexandria, Egypt. ICUs are Causality Care Unite I, General Intensive Care Unit II, and General Intensive Care Unit III.

Patients: One hundred nurse interns who received training in the previously mentioned setting and willing to participate in the study were included. This estimation is based on the power analysis (Epi Info program V7.0).

Tool: One tool was used: "Clinical Learning Environment, Supervision and Nurse Teacher (CLES + T) evaluation scale". It was developed by Saarikoski et al. ${ }^{(15)}$ It is used to assess CLE from NIs' point of view, supervision and the role of nurse preceptor within ICU. The scale composed of 5 subscales which included 34 items regarding aspects involved in clinical learning environment. The five subscales are: pedagogical atmosphere (9 items), leadership style of ICU manager (4 items), premises of nursing care in ICU (4items), supervisory relationship (8 items) and nurse teacher role in clinical area (9 items). NIs were asked to how much they believe these items affect CLE using a three points Likert type scale with three values; satisfied=3, nearly $=2$ and dissatisfied $=1$. Additionally, data were collected on NIs' sociodemographic data including sex, age, marital status, experience of work in private ICU.

\section{Method:}

- An official permission to conduct the study was obtained from "head of Critical Care \& Emergency Nursing Department", and "Nursing Ethical Committee" of Nursing Faculty- Alexandria University and hospital authority "Medical Ethical Committee" after explaining the aim of study.

- The tool CLES + T scale was translated into Arabic language. Content validity of the tool was tested by 5 experts in the field of critical care and emergency nursing and necessary modifications were done. The subscales' reliability values of these factors measured by Cronbach's coefficient Alpha, in which the internal consistency reliability ranged from 0.729 to 0.936 , while the statistical significance level was $p<0.05$.

- A pilot study was carried out on 10 intern nurses to evaluate the clarity and applicability of the tool and necessary modifications were done when needed. 
- Data was collected through a self-reported method. The questionnaire was introduced to intern nurses individually at break time of morning and evening shift after securing their consents and clarifying purpose of the study.

- Time needed for each interview ranged from 15 to 20 minutes. Data of the study was collected from April 2016 to October 2016.

\section{Ethical consideration:}

Intern nurses were informed that sharing in that study was voluntary. Written consent to participate in the study was obtained from them. The anonymity and confidentiality of responses were emphasized to intern nurses.

\section{Statistical analysis of the data}

Data were fed to the computer and analyzed using IBM SPSS software package version 20. Analysis and interpretation of data were done using the followings; Frequency, mean and standard deviation. Comparison between two independent population were done using independent $\mathrm{t}$-test while more than two population were analyzed F-test. $\mathrm{P}$ is significant if $\leq 0.05$.

\section{Results}

Table 1 illustrated the demographic characteristics of the studied intern nurses (NIs). The table shows that the majority of NIs were in the age group from 20 to 29 years old (90\%), female (83\%), and single (70\%), as well as more than half of them (64\%) had experience from 1 to 5 years in ICU.

Table 2 illustrates the relationship between general satisfaction of NIs measured by total CLES + T scale with the five subscales of CLES $+\mathrm{T}$. There was significant relation between the overall general satisfaction and all of the subscales dimensions $(\mathrm{p}=0.00)$.

Table 3 illustrates NIs' perception toward clinical learning environment (CLE) in ICU. NIs perceived that pedagogical atmosphere was the most first important dimension in CLE (mean percent score $=81.47 \pm 14.2$ ) with reference to that $95 \%$ of NIs were satisfied with calling them by their personal name plus $78 \%$ of them found both sufficient meaningful learning situations on ICU and enough clinical learning opportunities for their needs. In addition, low percent (37\%) of NIs reported feeling comfortable at the start of their shift in ICU. While, the leadership style of ICU manager dimension that was perceived as the least essential CLE one (mean percent score $=74.8 \pm 25.1)$. About half of NIs agreed that ICU manager appreciates nurses' effort $(60 \%)$ and their feedback could easily be considered a learning situation (52\%).

Table 4 reveals relationship between NIs' socio-demographic data with the five dimensions of CLE dimensions. The table revealed that significant relation between NIs' socio-demographic data of age, gender, marital status with their satisfaction with the five CLE dimensions. For age, the high percent of NIs with age below 20 years perceived CLE dimensions of premises of nursing in ICU as the most vital dimension ( $\mathrm{P}=0.001)$ while NIs with age from 20 to 29 years perceived CLE dimensions of nurse preceptor role as the most vital one $(\mathrm{P}=0.001)$. Regarding gender, there was a significant relation as high percent of male NIs agreed that supervisory relationship dimension was the most important CLE dimension. ( $\mathrm{P}=0.003)$. Furthermore, this study showed significant correlation between nurses' experience of working in ICU and both CLE dimensions of nurse preceptor role $(\mathrm{p}=0.003)$ and supervisory relationship $(\mathrm{p}=0.04)$.

Table (1): Distribution of the studied nurses according to socio-demographic characteristics $(\mathbf{n}=\mathbf{1 0 0})$.

\begin{tabular}{|l|l|c|c|}
\hline \multirow{2}{*}{ Sge } & Socio-demographic characteristics & No. & \% \\
\cline { 2 - 4 } & $<20$ & 9 & 9.0 \\
\hline \multirow{2}{*}{ Sex } & $20-29$ & 91 & 91.0 \\
\hline \multirow{2}{*}{ Marital status } & Male & 17 & 17.0 \\
\cline { 2 - 4 } & Female & 83 & 83.0 \\
\hline \multirow{2}{*}{ Experience of work in private ICU } & Single & 77 & 77.0 \\
\cline { 2 - 4 } & Married & 23 & 23.0 \\
\cline { 2 - 4 } & Yes & 64 & 64.0 \\
\cline { 2 - 4 } & No & 36 & 36.0 \\
\hline
\end{tabular}

Table 2: Correlations between general satisfaction measured by overall CLES + T scale with subscales of CLES+T

\begin{tabular}{|c|c|c|c|c|c|c|}
\hline $\begin{array}{c}\text { Satisfaction items } \\
\text { score }\end{array}$ & $\begin{array}{c}\text { Significanc } \\
\text { e test }\end{array}$ & \multicolumn{4}{|c|}{ Subscales of CLES+T scale } \\
\cline { 3 - 7 } & & $\begin{array}{c}\text { Pedagogical } \\
\text { atmosphere }\end{array}$ & $\begin{array}{c}\text { leadership } \\
\text { style of ICU } \\
\text { manager }\end{array}$ & $\begin{array}{c}\text { Premises of } \\
\text { nursing in } \\
\text { ICU }\end{array}$ & $\begin{array}{c}\text { Nurse } \\
\text { preceptor role }\end{array}$ & $\begin{array}{c}\text { Nurse } \\
\text { Supervisor } \\
\text { role }\end{array}$ \\
\hline $\begin{array}{c}\text { Overall CLES+T } \\
\text { scale }\end{array}$ & $\mathbf{R}$ & 0.843 & 0.784 & 0.773 & 0.769 & 0.808 \\
\cline { 2 - 7 } & $\mathbf{P}$ & 0.000 & 0.000 & 0.000 & 0.000 & 0.000 \\
\hline
\end{tabular}

r: Pearson coefficient $\quad *$ : Statistically significant at $\mathrm{p} \leq 0.05$ 
Nurse Interns' Satisfaction with Clinical Learning Environment in Intensive Care Unit

Table (3): Distribution of clinical learning environment dimensions according to nurse interns' satisfaction

\begin{tabular}{|c|c|c|c|c|c|c|c|c|}
\hline \multirow[t]{2}{*}{ CLES+T scale } & \multicolumn{2}{|c|}{ Satisfied } & \multicolumn{2}{|c|}{ Neutral } & \multicolumn{2}{|c|}{ Dissatisfied } & \multirow{2}{*}{$\begin{array}{c}\text { Total score } \\
\text { Min. - } \\
\text { Max. } \\
\text { Mean } \pm \text { SD. }\end{array}$} & \multirow{2}{*}{$\begin{array}{l}\text { Percent score } \\
\text { Min. - Max. } \\
\text { Mean } \pm \text { SD. }\end{array}$} \\
\hline & No. & $\%$ & No. & $\%$ & No. & $\%$ & & \\
\hline Pedagogical atmosphere & & & & & & & $\begin{array}{l}15.0-27.0 \\
23.7 \pm 2.6\end{array}$ & $\begin{array}{c}33.3-100.0 \\
81.7 \pm 14.2 \\
\end{array}$ \\
\hline I feel comfortable going to the ICU at the start of my shift. & 37 & 37.0 & 43 & 43.0 & 20 & 20.0 & & \\
\hline The staff calls me by my personal name. & 95 & 95.0 & 5 & 5.0 & 0 & 0.0 & & \\
\hline $\begin{array}{l}\text { I feel that staff was interested in my supervision as an } \\
\text { intern nurse }\end{array}$ & 44 & 44.0 & 48 & 48.0 & 8 & 8.0 & & \\
\hline $\begin{array}{l}\text { I felt comfortable taking part in discussion during nursing } \\
\text { round. }\end{array}$ & 76 & 76.0 & 22 & 22.0 & 2 & 2.0 & & \\
\hline The staff was easy to approach. & 45 & 45.0 & 53 & 53.0 & 2 & 2.0 & & \\
\hline $\begin{array}{l}\text { The learning situations were multi-dimensional in terms of } \\
\text { content }\end{array}$ & 72 & 72.0 & 28 & 28.0 & 0 & 0.0 & & \\
\hline $\begin{array}{l}\text { There were sufficient meaningful learning situations on } \\
\text { ICU. }\end{array}$ & 78 & 78.0 & 20 & 20.0 & 2 & 2.0 & & \\
\hline I have enough clinical learning opportunities for my needs & 78 & 78.0 & 20 & 20.0 & 2 & 2.0 & & \\
\hline The leadership style of ICU manager & & & & & & & $\begin{array}{l}4.0-12.0 \\
9.9 \pm 2.0 \\
\end{array}$ & $\begin{array}{l}0.0-100.0 \\
74.8 \pm 25.1\end{array}$ \\
\hline $\begin{array}{l}\text { ICU manager regards the staff on his/her ICU as a key } \\
\text { resource }\end{array}$ & 55 & 55.0 & 37 & 37.0 & 8 & 8.0 & & \\
\hline ICU manager acts as a team member & 67 & 67.0 & 19 & 19.0 & 14 & 14.0 & & \\
\hline $\begin{array}{l}\text { ICU manager feedback could easily be considered a } \\
\text { learning situation. }\end{array}$ & 52 & 52.0 & 42 & 42.0 & 6 & 6.0 & & \\
\hline ICU manager appreciates nurses' effort. & 60 & 60.0 & 32 & 32.0 & 8 & 8.0 & & \\
\hline Premises of nursing on ICU & & & & & & & $\begin{array}{l}6.0-12.0 \\
10.3 \pm 1.5\end{array}$ & $\begin{array}{c}25.0-100.0 \\
78.8 \pm 18.4\end{array}$ \\
\hline ICU philosophy is clearly defined. & 54 & 54.0 & 40 & 40.0 & 6 & 6.0 & & \\
\hline Individualized nursing care is provided & 56 & 56.0 & 44 & 44.0 & 0 & 0.0 & & \\
\hline Nursing documentation is clear. & 62 & 62.0 & 36 & 36.0 & 2 & 2.0 & & \\
\hline The flow of information related to patient's care is easy. & 70 & 70.0 & 26 & 26.0 & 4 & 4.0 & & \\
\hline Role nurse preceptors & & & & & & & $\begin{array}{l}11.0-27.0 \\
22.9 \pm 3.9\end{array}$ & $\begin{array}{l}11.1-100.0 \\
77.6 \pm 21.9\end{array}$ \\
\hline $\begin{array}{l}\text { Preceptors are capable of integrating theoretical knowledge } \\
\text { and everyday practice of nursing }\end{array}$ & 64 & 64.0 & 26 & 26.0 & 10 & 10.0 & & \\
\hline $\begin{array}{l}\text { Preceptors are capable of making plans to achieve the } \\
\text { learning objectives. }\end{array}$ & 65 & 65.0 & 25 & 25.0 & 10 & 10.0 & & \\
\hline preceptors encourages me to be an independent learner & 61 & 61.0 & 28 & 28.0 & 11 & 11.0 & & \\
\hline preceptors are like a member of the nursing team & 47 & 47.0 & 43 & 43.0 & 10 & 10.0 & & \\
\hline My preceptors are enthusiastic & 67 & 67.0 & 29 & 29.0 & 4 & 4.0 & & \\
\hline $\begin{array}{l}\text { My preceptors and the clinical team work together to } \\
\text { support my learning experience. }\end{array}$ & 64 & 64.0 & 27 & 27.0 & 9 & 9.0 & & \\
\hline $\begin{array}{l}\text { Preceptor is able to give his or her expertise to the nursing } \\
\text { team. }\end{array}$ & 65 & 65.0 & 33 & 33.0 & 2 & 2.0 & & \\
\hline $\begin{array}{l}\text { My preceptor has good communication with health care } \\
\text { team. }\end{array}$ & 78 & 78.0 & 20 & 20.0 & 2 & 2.0 & & \\
\hline $\begin{array}{l}\text { My preceptors provide me with regular feedback on my } \\
\text { strengths and weaknesses. }\end{array}$ & 62 & 62.0 & 16 & 16.0 & 22 & 22.0 & & \\
\hline Supervisory relationship4 & & & & & & & $\begin{array}{l}10.0-24.0 \\
20.5 \pm 3.1\end{array}$ & $\begin{array}{c}12.5-100.0 \\
77.8 \pm 19.6\end{array}$ \\
\hline I feel that I receive individual supervision & 66 & 66.0 & 33 & 33.0 & 1 & 1.0 & & \\
\hline I continuously receive feedback from my supervisor & 70 & 70.0 & 22 & 22.0 & 8 & 8.0 & & \\
\hline I am satisfied with the supervision I receive & 52 & 52.0 & 40 & 40.0 & 8 & 8.0 & & \\
\hline $\begin{array}{l}\text { Supervision was based on a relationship of equality and } \\
\text { promote my learning }\end{array}$ & 66 & 66.0 & 22 & 22.0 & 12 & 12.0 & & \\
\hline There is a mutual interaction in the supervisory relationship & 66 & 66.0 & 32 & 32.0 & 2 & 2.0 & & \\
\hline $\begin{array}{l}\text { The supervisory relationship is characterized by a sense of } \\
\text { trust }\end{array}$ & 59 & 59.0 & 31 & 31.0 & 10 & 10.0 & & \\
\hline I have good clinical supervision at all time & 52 & 52.0 & 32 & 32.0 & 16 & 16.0 & & \\
\hline Supervision enhance an atmosphere of mutual respects & 82 & 82.0 & 7 & 7.0 & 11 & 11.0 & & \\
\hline
\end{tabular}

Table (4): Distribution of the studied nurse interns according to their socio demographic characteristics in relation to clinical learning environment dimensions

\begin{tabular}{|c|c|c|c|c|c|c|c|c|c|c|}
\hline & \multicolumn{2}{|c|}{$\begin{array}{l}\text { Pedagogical } \\
\text { atmosphere }\end{array}$} & \multicolumn{2}{|c|}{$\begin{array}{l}\text { leadership style } \\
\text { of ICU manager }\end{array}$} & \multicolumn{2}{|c|}{$\begin{array}{c}\text { Premises of } \\
\text { nursing in ICU }\end{array}$} & \multicolumn{2}{|c|}{$\begin{array}{c}\text { Nurse preceptor } \\
\text { role }\end{array}$} & \multicolumn{2}{|c|}{$\begin{array}{c}\text { Nurse Supervisor } \\
\text { role }\end{array}$} \\
\hline & Mean & \pm SD. & Mean & \pm SD. & Mean & \pm SD. & Mean & \pm SD. & Mean & \pm SD. \\
\hline \multicolumn{11}{|l|}{ Age } \\
\hline$<20$ & 78.4 & 12.3 & 62.5 & 19.8 & 88.9 & 4.8 & 80.5 & 19.8 & 83.3 & 8.8 \\
\hline $20-29$ & 81.9 & 14.4 & 75.9 & 25.3 & 77.8 & 18.9 & 48.8 & 23.7 & 77.3 & 20.3 \\
\hline
\end{tabular}


Nurse Interns' Satisfaction with Clinical Learning Environment in Intensive Care Unit

\begin{tabular}{|c|c|c|c|c|c|c|c|c|c|c|}
\hline$t(p)$ & \multicolumn{2}{|c|}{$0.7(0.5)$} & \multicolumn{2}{|c|}{$1.5(0.1)$} & \multicolumn{2}{|c|}{$4.6^{*}\left(0.001^{*}\right)$} & \multicolumn{2}{|c|}{$4.5^{*}\left(0.001^{*}\right)$} & \multicolumn{2}{|c|}{$1.7(0.1)$} \\
\hline \multicolumn{11}{|l|}{ Sex } \\
\hline Male & 79.1 & 11.7 & 77.2 & 15.5 & 84.6 & 12.1 & 76.5 & 15.7 & 85.3 & 7.3 \\
\hline Female & 82.2 & 14.7 & 74.3 & 26.7 & 77.6 & 19.3 & 77.8 & 23.1 & 76.3 & 20.9 \\
\hline$t(p)$ & \multicolumn{2}{|c|}{$0.8(0.4)$} & \multicolumn{2}{|c|}{$0.6(0.5)$} & \multicolumn{2}{|c|}{$1.9(0.1)$} & \multicolumn{2}{|c|}{$0.2(0.8)$} & \multicolumn{2}{|c|}{$3.1^{*}\left(0.003^{*}\right)$} \\
\hline \multicolumn{11}{|l|}{ Marital status } \\
\hline Single & 82.1 & 14.9 & 74.4 & 23.9 & 79.7 & 18.6 & 78.4 & 19.9 & 75.8 & 23.9 \\
\hline Married & 80.2 & 11.9 & 76.1 & 29.2 & 75.5 & 17.9 & 75.8 & 18.8 & 83.6 & 12.7 \\
\hline$t(\mathbf{p})$ & \multicolumn{2}{|c|}{$0.7(0.6)$} & \multicolumn{2}{|c|}{$0.3(0.8)$} & \multicolumn{2}{|c|}{$0.9(0.3)$} & \multicolumn{2}{|c|}{$0.6(0.6)$} & \multicolumn{2}{|c|}{$2.04^{*}\left(0.04^{*}\right)$} \\
\hline \multicolumn{11}{|l|}{$\begin{array}{l}\text { Experience of work in } \\
\text { private ICU }\end{array}$} \\
\hline Yes & 82.8 & 15.3 & 74.8 & 25.7 & 76.8 & 16.9 & 73.7 & 25.8 & 80.8 & 19.6 \\
\hline No & 79.6 & 12.1 & 74.7 & 24.2 & 82.3 & 20.6 & 84.6 & 9.8 & 72.6 & 18.6 \\
\hline$t(p)$ & \multicolumn{2}{|c|}{$1.1(0.3)$} & \multicolumn{2}{|c|}{$0.03(0.9)$} & \multicolumn{2}{|c|}{$1.5(0.1)$} & \multicolumn{2}{|c|}{$3.01^{*}\left(0.003^{*}\right)$} & \multicolumn{2}{|c|}{$2.04^{*}\left(0.04^{*}\right)$} \\
\hline
\end{tabular}

$\mathrm{t}, \mathrm{p}: \mathrm{t}$ and $\mathrm{p}$ values for Student t-test

*: Statistically significant at $\mathrm{p} \leq 0.05$

F,p: F and p values for ANOVA test

\section{Discussion}

The current results largely revealed that nurse interns' (NIs) satisfaction with their clinical learning environment (CLE) was significantly related to all of the subscales CLES + T dimensions. This means that nurse interns accomplishing clinical practice in ICU expressed a rich established philosophy of nursing, individual patient care is given, an uncomplicated data flow and accurate well documentation of nursing practices. These findings are in agreement with previous ones concluding largely, nurse interns estimated the CLE positively, ${ }^{(16-18)}$ as well as other relevant studies documented that high percent of nurse students were satisfied with their clinical experience. ${ }^{(19-21)}$

It is a surprising result of the present study that high percent of NIs were satisfied with pedagogical atmosphere of ICU as the most first important dimension in CLE although ICU is a huge source of stressor. This means that NIs were able to take part in the discussion during nursing round and having enough clinical learning opportunities for their needs. Additionally, they experienced that ICU staff was easy to approach, deal friendly with them as calling them by their personal name, and generally interested in their supervision as an intern nurse plus NIs found sufficient meaningful learning situations on the ICU. These results were in line other Sundler et al's ${ }^{(22)}$ and Magnani et al's ${ }^{(6)}$ studies results. On the other hand, low percent of NIs reported feeling comfortable at the start of their shift in ICU. This may be due to NIs' point of view, CLE is the greatest anxiety aggravating element related to education of nursing. ${ }^{(23)}$

Regarding the leadership style of ICU manager, it is a form of organizational support that is needed and helpful when NIs' pre-existing knowledge and skills are inadequate for clinical practice ${ }^{(24)}$ High percent of NIs in this study were dissatisfied with the leadership style of ICU manager dimension and perceived it as the least essential CLE one. This can be explained by that ICU manager support remained less than NIs' expectation. NIs wasn't respected, appreciated and didn't receive feedback from ICU manager. Cowie et al. ${ }^{(25)}$ approved that ICU managers are not directly involved in clinical teaching or in the supervision of nursing students but responsibilities for allocating clinical placements for nursing students. Bezuidenhout et al. (26) added that leadership within nursing is based upon the ability to influence the staff toward the achievement of goals through motivation and support. In addition, it was approved that high level of satisfaction has been reported when students had the nurse manager ensuring that their learning needs were addressed as she was well updated. ${ }^{(27)}$

About nurse preceptor role, the current study revealed that some NIs dissatisfied with this role. They found nurse preceptor didn't provide them with regular feedback on their strengths and weaknesses. This result was augmented by Levett-Jones et al ${ }^{(28)}$ who approved that students need feedback and to maintain open communications with their faculty trainers. Researches ${ }^{(29,30)}$ revealed that nurse preceptor is considered to be a nurse who is in charge for alert designing of the practical placements, and hence consistent appointments improved NIs' practical experience because those appointments confirmed that intended learning outcomes were successfully completed in exact approach.

Moreover, the present study showed that high percent of NIs in age group less than 20 years and without experience found nurse preceptor role was significantly important for them. This can be due to that they were unprepared psychologically and had a sense of still attaching completely to their faculty and needed support from it. Unexperienced NIs considered ICU setting as a new stressful clinical one. This was accepted by several relevant studies which documented that the nurse preceptor role effective, especially in stressful situations. Sundler et al. ${ }^{(31)}$ concluding that a nurse preceptor had a direct influence on NIs' satisfaction with CLE. Moreover, inexperience results in fear of making mistakes, feeling of incompetent and low selfconfidence. This result was accepted by Edwards et al. ${ }^{(32)}$ and Joolaee et al. ${ }^{(33)}$ who demonstrated that inadequate self-confidence is a great problem for new nurses causing feeling of anxiety and fear. 
While these results demonstrated that high percent of married NIs in the age group from 20 to 30 years plus who with experience of work in ICU were satisfied with nurse supervisor role significantly and considered it important CLE dimension for them. This is attributed to NIs' familiarity with ICU setting as well as meeting and caring for critically ill patients. Additionally, it was expected that these NIs exposed to situational problems and gained experience from solving. Therefore, it was easier for these NIs to approach the staff with questions without being judged as less competent. This is in line with Dornan ${ }^{(34)}$ who concluded that experienced students have the probability to deal with nurse supervisor more than other students. In addition, Van der Zwet et al ${ }^{(35)}$ found that experienced students fell more trust and the supervisor let them to take care of patients more independently.

\section{Conclusion}

It can be concluded that there was significant relation between the overall general NIs' satisfaction and the entire studied CLE dimensions. Additionally, high percent of NIs were satisfied with pedagogical atmosphere of ICU although ICU is a stressful environment as they able to have enough clinical learning opportunities for their needs. While high percent of NIs were dissatisfied with Leadership style of ICU manager which needs to be improved. Moreover, some NIs dissatisfied with nurse preceptor role. In the same time high percent of NIs in age group less than 20 years and without experience found nurse preceptor role was significantly important for them. Additionally, high percent of married NIs in the age group from 20 to 30 years with experience of work in ICU were satisfied with nurse supervisor role significantly and considered it important CLE dimension for them.

\section{Recommendations}

Nurse manager in ICU should be more cooperative with faculty to facilitate leaning for attaining positive intensive care nurse interns' perception and satisfaction with ICU environment. This will increase nurses' recruitment in ICU later on. Nurse preceptor should provide nurse interns with regular feedback on their strengths and weaknesses. Further study is needed to investigate the impact of clinical learning environment improvement on intern nurses' performance.

\section{References}

[1] Henderson A, Briggs J., Schoonbeek S. \& Paterson K. A framework to develop a clinical learning culture in health facilities: ideas from the literature, International Nursing Review 2011; 58: 196-202.

[2] Lakanmaa RL, Suominen T, Perttilä J, Ritmala-Castrén M, Vahlberg T, Leino-Kilpi H. Basic competence in intensive and critical care nursing: development and psychometric testing of a competence scale. Journal of clinical nurse 2014; 23(5-6):799-810.

[3] Semdley A, Morey P. Improving learning in the clinical nursing environment perception of senior Australian bachelor of nursing students. Journal of Research in Nursing 2009; 15(1):88-75.

[4] Chan DSK .Development of an innovative tool to assess hospital learning environment. Nurse Education today 2001;21(8):624-31.

[5] Skaalvik MW, Normann HK, Henriksen N. Clinical learning environment and supervision: experiences of Norwegian nursing students. A questionnaire survey. Journal of Clinical Nursing. 2011; 20 (15-16): 2294-304. doi: 10.1111/j.1365-2702.2011.03727.x.

[6] Magnani, D, Lorenzo, RD, Bari, A, Pozzi, S, Giovane, CD, Ferri, P. The undergraduate nursing student evaluation of clinical learning environment: an Italian survey. Professioni Infermieristiche 2014; 67(1): 55-61.

[7] Victor G, Ishtiaq M. perception of clinical environment among nursing student of a private college of nursing in Pakistan. Med Channel 2016; 22(2): 33-40.

[8] Orton H. Ward learning climate and student nurse response. Nursing Times Occasional Papers 1981; 77(17).

[9] Fretwell J. Creating a ward-learning environment: the sister's role. Nursing Times Occasional Papers 1983; 79(21\&22).

[10] Borrageiro F. Clinical Learning Environment and Supervision: Student Nurses Experiences within Private Health Care Settings In The Western Cape. SUN Scholar Research Repository 2014.

[11] Jamshidi L. The challenges of clinical teaching in nursing skills and life-long learning from the standpoint of nursing students and educators. Procedia-social and behavioral science 2012; 46:3335-8.

[12] Debisette A. Addressing new challenges facing nursing education, solutions for a transforming health care environment. The national advisory council on nurse education and practice 2010:1-34.

[13] Löfmark, A, Wikblad, K. Facilitating and obstructing factors for development of learning in clinical practice: a student perspective. Journal of Advanced Nursing 2001; 34(1):43-50.

[14] Spouse, J. Workplace learning: pre-registration nursing students' perspectives. Nurse Education in Practice 2001; 1(3):149-56.

[15] Saarikoski M, Isoaho H, Warne T, Leino-Kilpi H. The nurse teacher in clinical practice: Developing the new sub-dimension to the clinical learning environment and supervision (CLES) scale. International Journal of Nursing Studies 2008; 45: 1233 -47.

[16] Cremonini V, Ferri P, Artioli G, Sarli L, Enrico Piccioni E, Rubbi I. Nursing students' experiences of and satisfaction with the clinical learning environment: the role of educational models in the simulation laboratory and in clinical practice. Acta Biomed for Health Professions 2015; 86(3): 194-204.

[17] Warne T, Johansson UB, Papastavrou E, et al. An exploration of the clinical learning experience of nursing students in nine European countries. Nurse Education Today 2010; 30: 809-15.

[18] Comparcini D, Simonetti V, Tomietto M, et al. Nursing students' satisfaction and perception of their first clinical placement: observational study. Professioni Infermieristiche 2014; 67: 41-7.

[19] Dimitriadou M, Papastavrou E, Efstathiou G, Theodorou M. Baccalaureate nursing students' perceptions of learning and supervision in the clinical environment. Nurs Health Sci. 2015;17: 236-42.

[20] Bisholt B, Ohlsson U, Engström AK, Johansson AS, Gustafsson M. Nursing students' assessment of the learning environment in different clinical settings. Nurse Educ Pract. 2014;14: 304-10. 
[21] Skaalvik MW, Normann HK, Henriksen N. Clinical learning environment and supervision: experiences of Norwegian nursing students - a questionnaire survey. Journal of Clinical Nursing 2011; 20: 2294-304

[22] Sundler AJ, Björk M, Bisholt B, Ohlsson U, Engström AK, Gustafsson M. Student nurses' experiences of the clinical learning environment in relation to the organization of supervision: a questionnaire survey. Nurse Education Today 2014; 34 : 661-6.

[23] Papastavro E, Maria Dimitriadou M, Tsangari H, Andreou C. Nursing students' satisfaction of the clinical learning environment: a research study BMC Nursing 2016; 15: 44. DOI 10.1186/s12912-016-0164-4.

[24] Tsai JC, Chen CS, Sun F, Liu km and Chung-Sheng Lai cs. Clinical learning environment measurement for medical trainees at transitions: relations with socio-cultural factors and mental distress. BMC Medical Education 2014; 14:226.

[25] Cowie H, Smith P, Lorentzon M. Leadership for learning: a literature study of leadership for learning in clinical practice. Surrey Scholarship Online. Faculty of Health and Medical Sciences. Surrey University 2008. http://epubs.surrey.ac.uk/divHealth socialCare/1.

[26] Bezuidenhout MC, Koch S, Netshandama VO. The role of the ward manager increating a conducive clinical learning environment for nursing students. Research Article 1999.

[27] Bisholt B, Ohlsson U, Engström AK, Johansson AS, Gustafsson M. Nursing students' assessment of the learning environment in different clinical settings. Nurse Education in Practice. 2014; 14: 304-10.

[28] Levett-Jones T1, Lathlean J, Higgins I, McMillan M. Staff-student relationships and their impact on nursing students belongingness and learning. Journal of Advanced Nursing. 2009; 65(2):316-24. doi: 10.1111/j.1365-648.2008.04865.x.

[29] Christiansen A, Prescott T, Ball J. Learning in action: developing safety improvement capabilities through action learning. Nurse Education Today 2014; 34: 243-7.

[30] Gustafsson M, Kullén Engström A, Ohlsson U, Sundler AJ, Bisholt B. Nurse teacher models in clinical education from the perspective of student nurses - A mixed method study. Nurse Education Today 2015.

[31] Sundler AJ, Björk M, Bisholt B, Ohlsson U, Engström Kullén A, Gustafsson M. Nursing students' experiences of the clinical learning environment in relation to the organisation of supervision: a questionnaire study. Nurse Education Today 2013.

[32] D. Edwards, P. Burnard, K. Bennett, and U. Hebden. A longitudinal study of stress and self-esteem in student nurses. Nurse Education Today 2010; 30(1): 78-84.

[33] Joolaee S, Jafarian Amiri SR, Farahani MA, Varaei S. Iranian nursing students' preparedness for clinical training: a qualitative study. Nurse Education Today 2015; 35(10): e13-e17.

[34] Dornan T, Boshuizen H, King N, Scherpbier A. Experience-based learning: a model linking the processes and outcomes of medical students' workplace learning. Medical Education 2007; 41: 84-91.

[35] Van der Zwet J, Zwietering PJ, Teunissen PW, Van der Vleuten CPM, Scherpbier AJJA. Workplace learning from a socio-cultural perspective: creating developmental space during the general practice clerkship. Advances in Health Sciences Education 2011; 16: 359-73. 